\title{
Erosive tooth wear symposium planned
}

A symposium entitled 'A Practical

Approach to BEWE [the basic erosive wear examination] \& Management of Erosive Tooth Wear in Practice' will be held on Friday 17 April 2020 from 10:30 to 16:15 at Tower Lecture Theatre, Guy's Hospital, London.

Although tooth wear is the third most commonly observed oral condition, very few dental professionals are screening patients and recording erosive tooth wear (ETW) in patient records.

The symposium, developed for dentists, dental hygienists and dental therapists, is free to attend and will provide you with practical advice on management of ETW, from how to use the BEWE to useful hints on the effective restorative management of ETW in practice.

The event will be hosted by The Erosive Tooth Wear Foundation and KCL, and sponsored by GSK, and will bring together clinical experts in restorative dentistry

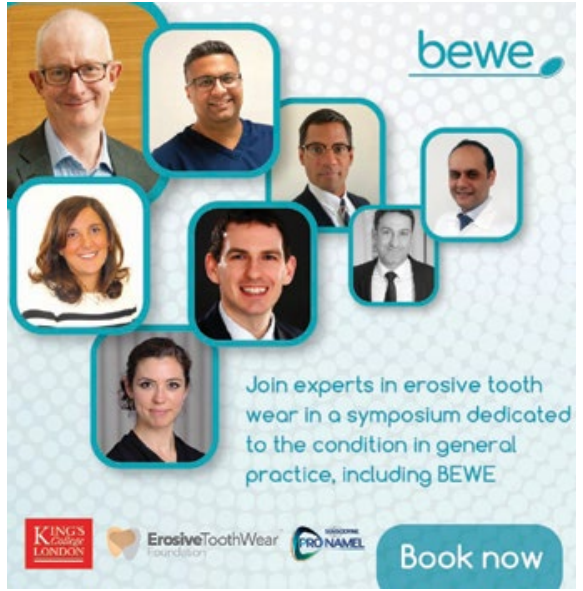

and dentolegal experts to provide you with a practical 'nuts to bolts' overview of successful management in general practice. Speakers will include David Bartlett, Saoirse O'Toole, Shamir Mehta and Sachin Varma. CPD will also be provided.

For more information and to book your place, visit www.bewe.eventbrite.co.uk.

\section{Join an MCN meeting}

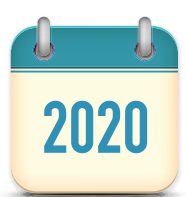

The Midlands Secure Setting Managed

Clinical Network (MCN) invites all dental teams working within secure settings in the Midlands region to attend a meeting. Below are the dates for the remainder of MCN meetings for 2020:

- 21 March 2020, 10:00-14:30, County Hospital Postgraduate Medical Centre, Stafford

- 4 July 2020, 10:00-14:30, Venue TBC

- 12 September 2020, 10:00-14:30, Venue TBC

If you wish to attend, please contact the MCN Chair: Sunita Moodley -

Sunita.Moodley@nhft.nhs.uk.

\section{FGDP(UK) North West Division Study Day 2020}

October 2019 saw the inaugural FGDP (UK) North West Division Study Day take place at Etihad Stadium to an enthusiastic response from attending delegates and exhibitors. The event returns to Manchester on 13 November 2020 at the stunning Science + Industry Museum in the heart of the city where we will be joined by speakers Ian Dunn and Serpil Djemal (pictured).

Ian Dunn is the Perio Lead for the Faculty of General Dental Practitioners and runs their short course in Periodontics and leads the Perio components of the FGDP Restorative Diploma. His sessions will focus on Contemporary Periodontal Practice providing a modern understanding of aetiology, assessment and diagnosis, and looking at motivating patients to achieve high standards of home care to achieve non-surgical management of periodontal disease.

Serpil Djemal is actively involved in the acute and long term management of patients who have sustained traumatic dental injuries and is also the founder chairperson of Dental Trauma UK - a new charity set up to raise public and professional awareness in the prevention and management of traumatic dental injuries. Serpil will present 'Crash bang wallop - modern management of dental trauma' - giving all members of the dental team a better understanding of the presentation and management of traumatic dental injuries with a focus on the management of dental fractures and the management of luxation injuries.

A large number of exhibitors and sponsors will also be joining the study day - giving you the chance to meet your suppliers and find out about the latest innovations, plus, there will be a networking event after the main scientific programme.

Six hours of CPD, world class speakers, and great networking opportunities will all be part of the occasion. To book places for you and your team go to https://www. fgdp-nw.com/book-manchester-study-day/.

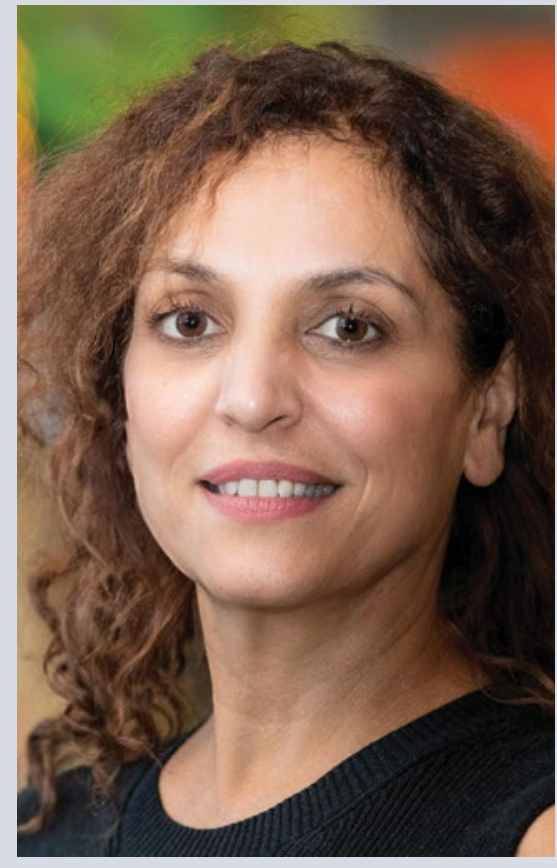

Serpil Djemal, founder chairperson of Dental Trauma UK

The spring rate booking runs until the end of April. 